\title{
Transformational Leadership and Organizational Climate of Educational Institutions Along Thai-Cambodian Borders \\ Dr.Poonsook Kitratporn
}

Assistant Professor-Graduate Diploma, Thai Program

\section{Dr.Vichian Puncreobutr}

Lecturer-M.Ed. English Program, St. Theresa International College, Thailand

\section{Doi:10.5901/mjss.2016.v7n3s1p470}

\begin{abstract}
The purpose of this research was to study the Transformational Leadership and Organizational Climate of educational institutions along Thai-Cambodian borders, preparing for the integration into the ASEAN economic community. The simple random sample chosen for the study were administrators and teachers with the sample size of 384 based on Krejcie Morgan table. Questionnaire was used to collect data from the respondents and the statistical tools used in the study were Mean, TTest and Pearson's Simple Correlation. The variables gender, size of school and working status were considered for the study to find out the significant differences towards transformational leadership and organizational climate. And the relationship between two variables was measured i.e. transformational leadership and organizational climate. The result confirmed that there is a significant difference among the gender, size of school and working status towards transformational leadership and organizational climate. Moreover, it has shown the differences with female respondents, medium-sized school and administrators towards transformational leadership and organizational climate. The result of correlation revealed that there was a positive moderate relationship between transformational leadership and organizational climate at .639. However, the strong association between the individual dimensions was not found. Further, to probe, the educational institutions need to develop transformational leadership to create good organizational climate to compete in ASEAN economic community.
\end{abstract}

Keywords: transformational leadership; organizational climate; educational institutions; ASEAN

\section{Introduction}

The trend of dynamic changes around the world, lead many countries to prepare themselves for increasing potentials, especially the 10 member countries in Southeast Asian region, have come together and formed the ASEAN Economic Community (Thani Sukkasem, 2012). This is with the objective to increase bargaining power and ability to compete business in the international arena (ASEAN, 2009) to unite as one community. And this will not happen, if these member countries lack in the awareness of sharing or creating unity (Praepat Yodkaew, 2012), and for this, education is an important mechanisms to instill values.

The understanding among ASEAN member countries was instrumental in preparing them for stepping into ASEAN Economic Community (Secretary Office of the Education Council, 2006), so as to achieve learning methods and management in the ASEAN Economic Community.

The Commission of Basic Education encourages educational institutions/schools to develop a systematic implementation. (Secretariat Office of the Education Council, 2009; Office of the Commission of Basic Education, 2011), and for this purpose, the management has an important role in driving the mechanism (Thira Runcharoen, 2007) to create competencies and capability in administration and performance.

(Nakrob Rawangkan and Naruenan Suriyamanee, 2012) stated that one of the important abilities of educational administrators is using Transformational Leadership (Bass, 1985) and the Administration that creates good Organizational Climate (Robbins, 1990), especially the schools located in border areas which should be given more importance.

Based on the emerging importance, the researcher believes that, the study should be conducted to measure the correlation between Transformational Leadership and Organizational Climate of educational institutions along the ThaiCambodia borders. And also, to evaluate the administration performance of schools and educational administrators, who follow the policies properly for ASEAN community integration. The results of the study would be useful for developmental planning of school and educational administrators for stepping into ASEAN Economic Community in the next phase. 


\section{Literature Review}

Many studies have confirmed the existence of relationship between transformational leadership and organizational climate. Burns (1978) was the first to introduce the term transformational leadership. Later Bass (1985) has developed a model for transformational leadership in order to study the behavior of leaders. Also, it was viewed by him that transformational leaders affect followers. The four components of transformational leadership are idealized influence, inspirational motivation, Intellectual simulation and Individualized consideration. Georgopovles (1960) defined, Organizational Climate as a normative structure of attitudes and behavioural standards which provide a basis for interpreting the situations and act as a source of pressure for directing activities. Litwin and Stringer (1968) stated that Organizational Climate as a relatively enduring quality of the internal environment that is experimental by its members, influence their behavior and can be described in terms of the values of a particular set of characteristics of the organization. According to Moolenaar (2010) transformational leadership helps to attain innovative organizational climate and motivates followers in line with the works of (Bass, 1985). Phothong (2016) found that there is relationship between leadership and work climate. The result of Carley, Peters and Deckman (2014) indicated that there is good relationship between transformational leadership and organizational climate.

\section{Objectives of the Research}

To study the level of Transformational Leadership of educational institutions along the Thai-Cambodian borders preparing for integration into the ASEAN Economic Community.

* To study the level of Organizational Climate of schools (educational institutions) along the Thai-Cambodian borders preparing for integration into the ASEAN Economic Community.

* To compare the level of Transformational Leadership of educational institution administrators classified based on gender, size of school and working status.

* To compare the level of Organizational Climate of school or educational administrators classified based on gender, size of school and working status.

* To measure the relationship between Transformational Leadership and Organizational Climate of educational institutions along the Thai - Cambodian borders.

\section{Research Methodology}

In order to meet the objectives of the study, the researcher chosen a population of 100,000 administrators and teachers in schools (educational institutions) located along the Thai-Cambodian borders, who were preparing for integration into the ASEAN Economic Community. The sampling method adopted for the study is simple random sampling. And the estimated sample size of the study is 384 based on Krejcie and Morgan Table. The statistical methods used for the study are mean, T-Test and Pearson's Simple Correlation.

\section{Variables Used for the Research}

The variables are the gender, size of schools and working status.

The dependent variables are 1) Transformational Leadership of educational institutions administrator based on the concept of Bass (1985) that consists of Idealized Influence (II), Inspiration motivation (IM), Intellectual Stimulation (IS), Individualized Consideration (IC) and, 2) Organizational Climate based on the concept of Stringer (1977) consisting of Affinitive Climate, Authoritarian Climate, Achievement Climate.

The research instrument was constructed by the researcher, which has shown a discrimination of $.47-.83$ and Cronbach alpha value is at .91, which holds high reliability. The statistical tools used for this study are Mean, T-Test and Pearson's Simple Correlation.

\section{Data Analysis and Interpretation}

\subsection{Basic data}

The basic profile of the respondents was classified by gender, size of school and working status. 
Table 1. Shows the basic profile of the respondents

\begin{tabular}{|l|l|c|c|}
\hline Variables & Groups & Frequency & Percentage \\
\hline \multirow{3}{*}{ Gender } & Male & 123 & 32.0 \\
\cline { 2 - 4 } & Female & 261 & 68.0 \\
\hline \multirow{2}{*}{ Size of schools } & Small & 159 & 41.4 \\
\cline { 2 - 4 } & Medium & 225 & 58.6 \\
\hline \multirow{2}{*}{ Status } & Administrators & 114 & 29.7 \\
\cline { 2 - 4 } & Teachers & 270 & 70.3 \\
\hline
\end{tabular}

From the Table 1, it is shown that 261 respondents were female accounted for $68 \%$ and 123 respondents were male $32 \%$ respectively. And $58.6 \%$ of the schools were medium-sized, whereas $41.4 \%$ of the schools were small sized. Moreover, the number of teachers and administrators accounted for $70.3 \%$ and $29.7 \%$ respectively.

\subsection{The study on the level of Transformational Leadership}

The level of Transformational Leadership of the educational administrators along Thai-Cambodian borders as shown in the Table 2.

Table 2. Shows the overall level of Transformational Leadership ( $N=384)$

\begin{tabular}{l|c|c|c}
\hline Item & Mean & S.D. & Level of leadership \\
\hline Idealized Influence (II) & 4.235 & .6176 & High \\
Inspiration motivation (IM) & 4.333 & .5802 & High \\
Intellectual Stimulation (IS) & 4.354 & .5620 & High \\
Individualized Consideration (IC) & 4.313 & .6297 & High \\
\hline Transformational Leadership & 4.309 & .4708 & High \\
\hline
\end{tabular}

From the table 2, it found that the level of Transformational Leadership of educational institutions or school administrators along the Thai - Cambodian borders is at high level. The overall mean score is at 4.309. And while considering each dimension of transformational leadership, all items scores high. The result indicates that the dimension Intellectual Stimulation is the highest among all items, followed by the Inspirational motivation and Individualized Consideration respectively.

\subsection{The study on the level of Organizational Climate}

The level of organizational climate of schools or educational institutions for entering the ASEAN Economic Community along the Thai - Cambodia borders, as shown in Table 3.

Table 3. Shows the overall level of Organizational Climate $(N=384)$

\begin{tabular}{l|c|c|c}
\hline Item & Mean & S.D. & Level of climate \\
\hline Affinitive Climate & 4.419 & .5084 & High \\
Authoritarian Climate & 4.251 & .6370 & High \\
Achievement Climate & 4.283 & .6311 & High \\
\hline Organizational Climate & 4.324 & .4897 & High \\
\hline
\end{tabular}

From the table 3, it is understood that the level of Organizational Climate, of schools or educational institutions along the Thai-Cambodian borders is at high level (Average 4.324). While considering for each dimension of organizational climate, it was found that all items scores high. The result indicates that among the 3 dimensions of organizational climate, the item Affinitive Climate scores high later followed by the Achievement Climate and. the Authoritarian Climate respectively.

\subsection{Comparison of Transformational Leadership}

Comparing Transformational Leadership based on gender, size of schools and working status of the respondents as shown in Table 4-6. 


\subsection{Hypothesis}

Ho: There is no significance difference among gender towards transformational leadership.

$\mathrm{H} 1$ : There is a significant difference among gender towards transformational leadership.

Table 4. Comparing the level of Transformational Leadership classified by gender

\begin{tabular}{|c|c|c|c|c|c|c|}
\hline \multirow{2}{*}{ Item } & \multicolumn{2}{|c|}{ Male $(\mathrm{N}=123)$} & \multicolumn{2}{|c|}{ Female(N=261) } & \multirow{2}{*}{$\mathrm{t}$} & \multirow{2}{*}{$\mathrm{P}$} \\
\hline & Mean & S.D. & Mean & S.D. & & \\
\hline Idealized Influence (II) & 4.158 & .6126 & 4.271 & .6178 & -1.670 & .096 \\
\hline Inspiration motivation (IM) & 4.207 & .6220 & 4.392 & .5507 & $-2.951^{*}$ & .003 \\
\hline Intellectual Stimulation (IS) & 4.219 & .6390 & 4.418 & .5107 & $-3.029^{* *}$ & .003 \\
\hline Individualized Consideration (IC) & 4.239 & .6324 & 4.347 & .6267 & -1.569 & .117 \\
\hline Transformational Leadership & 4.206 & .4932 & 4.357 & .4528 & $-2.966^{* *}$ & .003 \\
\hline
\end{tabular}

From Table 4 it is evidenced that, for few dimensions (IM, IS), there is a significant difference among the respondents based on gender. The dimensions Idealized Influence and Individualized Consideration is statistically insignificant and greater than $p>0.05$, hence there is no significant difference among the respondents opinion for these two dimensions. Further, in over all the transformational leadership is at $p<0.01$ level, hence it can be concluded that there is a significant difference among the respondents based on gender. Hence $\mathrm{Ho}$ is rejected. The mean score comparison indicates that female respondents agree that transformational leadership is at high level, when compared to male respondents.

\subsection{Hypothesis}

Ho: There is no significance difference between different size of schools towards transformational leadership. $\mathrm{H} 1$ : There is a significant difference between different size of schools towards transformational leadership.

Table 5. Comparison of Transformational Leadership classified by size of schools

\begin{tabular}{|c|c|c|c|c|c|c|}
\hline \multirow{2}{*}{ Item } & \multicolumn{2}{|c|}{ Small(N=159) } & \multicolumn{2}{|c|}{ Medium( $(\mathrm{N}=225)$} & \multirow{2}{*}{$\mathrm{T}$} & \multirow{2}{*}{$\mathrm{P}$} \\
\hline & Mean & S.D. & Mean & S.D. & & \\
\hline Idealized Influence (II) & 3.965 & .5989 & 4.425 & .5577 & $-7.722^{* *}$ & .000 \\
\hline Inspiration motivation (IM) & 4.053 & .5875 & 4.531 & .4871 & $-8.683^{* *}$ & .000 \\
\hline Intellectual Stimulation (IS) & 4.187 & .5201 & 4.473 & .5613 & $-5.072^{* *}$ & .000 \\
\hline Individualized Consideration (IC) & 4.130 & .6486 & 4.422 & .5839 & $-4.920^{* *}$ & .000 \\
\hline Transformational Leadership & 4.084 & .4005 & 4.681 & .4523 & $-8.585^{* *}$ & .000 \\
\hline
\end{tabular}

From Table 5, it is examined that there is a significant difference between the sizes of school towards transformational leadership $(P<0.05$ level). Ho is rejected. While comparing among sizes of school, the medium sized schools scored high towards transformational leadership. And it is revealed that small sized schools scores low towards transformational leadership, when compared with medium sized schools.

\subsection{Hypothesis}

Ho: There is no significance difference between working status of respondents towards transformational leadership. $\mathrm{H} 1$ : There is a significant difference between working status of respondents towards transformational leadership.

Table 6. Comparison of Transformational Leadership classified by working status

\begin{tabular}{lcccccc}
\hline \multirow{2}{*}{ Item } & \multicolumn{2}{c}{ Administrator $(\mathrm{N}=114)$} & \multicolumn{2}{c}{ Teacher $(\mathrm{N}=270)$} & \multirow{2}{*}{$\mathrm{T}$} & $\mathrm{P}$ \\
\cline { 2 - 5 } & Mean & S.D. & Mean & S.D. & & \\
\hline Idealized Influence (II) & 4.318 & .6251 & 4.200 & .6122 & 1.715 & .087 \\
\hline
\end{tabular}




\begin{tabular}{|c|c|c|c|c|c|c|}
\hline Inspiration motivation (IM) & 4.460 & .4995 & 4.279 & .6040 & $2.816^{* *}$ & .005 \\
\hline Intellectual Stimulation (IS) & 4.390 & .6258 & 4.339 & .5333 & .805 & .421 \\
\hline Individualized Consideration (IC) & 4.388 & .5742 & 4.281 & .6502 & 1.519 & .130 \\
\hline Transformational Leadership & 4.389 & .4849 & 4.275 & .4615 & $2.179^{*}$ & .030 \\
\hline
\end{tabular}

From Table 6, it is manifested that there is no significant difference among teachers and administrators for three dimensions, which $P$-value $(P>0.05)$ level statistically insignificant, where as the significant difference exists for the item Inspirational Motivation at $P<0.01$ level. Further, in overall the transformational leadership is at $P<0.05$, hence, it can be concluded there is a significant difference among the respondents based on working status. Hence Ho is rejected. Besides the mean scores indicates that administrators agree that transformational leadership is at high level, when compared to teachers.

\section{Comparison of Organizational Climate}

Comparison of Organizational Climate based on gender, size of school and working status as shown in Table 7-9

\subsection{Hypothesis}

$\mathrm{Ho}$ : There is no significance difference among gender towards organizational climate.

$\mathrm{H} 1$ : There is a significant difference among gender towards organizational climate.

Table 7. Comparison of Organizational Climate classified by gender

\begin{tabular}{|c|c|c|c|c|c|c|}
\hline \multirow{2}{*}{ Item } & \multicolumn{2}{|c|}{ Male $(\mathrm{N}=123)$} & \multicolumn{2}{|c|}{ Female $(\mathrm{N}=261)$} & \multirow{2}{*}{$\mathrm{t}$} & \multirow{2}{*}{$P$} \\
\hline & Mean & S.D. & Mean & S.D. & & \\
\hline Affinitive Climate & 4.345 & .4666 & 4.454 & .5242 & -1.958 & .051 \\
\hline Authoritarian Climate & 4.157 & .6434 & 4.296 & .6303 & $-2.004^{*}$ & .046 \\
\hline Achievement Climate & 4.209 & .6808 & 4.319 & .6045 & -1.525 & .129 \\
\hline Organizational Climate & 4.244 & .5018 & 4.361 & .4803 & $-2.165^{*}$ & .031 \\
\hline
\end{tabular}

From the Table 7, it is revealed that there is a significant difference among the respondents based on gender towards organizational climate at $p$-value $(P<0.05)$. Whereas the item, achievement climate has no significant difference towards organizational climate and which is statistically insignificant. By considering the overall organizational climate it can be concluded that there is a significant difference among the respondents at $\mathrm{P}<0.01$ level. Hence Ho is rejected. While comparing the mean value of gender, female respondents agree the existence of organizational climate is at high level.

\subsection{Hypothesis}

Ho: There is no significance difference between size of schools towards organizational climate. $\mathrm{H1}$ : There is a significant difference between size of schools towards organizational climate.

Table 8. Comparison of Organizational Climate classified by size of the school

\begin{tabular}{|c|c|c|c|c|c|c|}
\hline \multirow{2}{*}{ Item } & \multicolumn{2}{|c|}{ Small $(N=159)$} & \multicolumn{2}{|c|}{ Medium $(\mathrm{N}=225)$} & \multirow{2}{*}{$\mathrm{t}$} & \multirow{2}{*}{$P$} \\
\hline & Mean & S.D. & Mean & S.D. & & \\
\hline Affinitive Climate & 4.251 & 5781 & 4.537 & 4148 & $-5.345^{* *}$ & .000 \\
\hline Authoritarian Climate & 4.058 & .7570 & 4.388 & .4944 & $-4.810^{* *}$ & .000 \\
\hline Achievement Climate & 4.174 & 6350 & 4.361 & 6181 & $-2.881^{* *}$ & .004 \\
\hline Organizational Climate & 4.171 & 5354 & 4.432 & .4235 & $-5.133^{* *}$ & .000 \\
\hline
\end{tabular}

From Table 8, it is reflected that there is a significant difference among the size of school towards organizational climate, which is statistically significant at $p<0.01$. Ho is rejected. The mean score of medium sized schools is greater than small sized school, which indicates good organizational climate prevailing in those schools. 


\subsection{Hypothesis}

Ho: There is no significance difference between working status of respondents towards transformational leadership. $\mathrm{H1}$ : There is a significant difference between working status of respondents towards transformational leadership.

Tables 9. Comparison of Organizational Climate classified by working status

\begin{tabular}{|c|c|c|c|c|c|c|}
\hline \multirow{2}{*}{ Item } & \multicolumn{2}{|c|}{ Administrator $(\mathrm{N}=159)$} & \multicolumn{2}{|c|}{ Teacher $(\mathrm{N}=225)$} & \multirow{2}{*}{$\mathrm{T}$} & \multirow{2}{*}{$P$} \\
\hline & Mean & S.D. & Mean & S.D. & & \\
\hline Affinitive Climate & 4.506 & .4529 & 4.382 & .5265 & $2.198^{*}$ & .029 \\
\hline Authoritarian Climate & 4.412 & .5252 & 4.184 & .6681 & $3.577^{* *}$ & .000 \\
\hline Achievement Climate & 4.396 & .5453 & 4.236 & .6591 & $2.476^{*}$ & .014 \\
\hline Organizational Climate & 4.441 & .4236 & 4.275 & .5078 & $3.066^{* *}$ & .002 \\
\hline
\end{tabular}

From Table 9 , it is observed that there is a significant difference among administrators and teachers towards Organizational Climate, which is statistically significant at $\mathrm{P}<0.01 \& \mathrm{P}<0.05$ level respectively. Hence, Ho is rejected. The mean score of administrators is high when compared to teachers; hence the administrators strongly agree that there is a good organizational climate prevailing in the organization.

\section{Measuring the Relationship between Transformational Leadership and Organizational Climate}

Measuring the relationship between Transformational Leadership and Organizational Climate of schools or educational institutions along the Thai - Cambodian borders as shown in Table 10

\subsection{Hypothesis}

There is a positive association between transformational leadership and organizational climate.

Table 10. Relationship between Transformational Leadership and Organizational Climate

\begin{tabular}{|l|l|l|l|l|l|l|}
\hline & & $\mathrm{I}$ & $\mathrm{IM}$ & $\mathrm{IS}$ & $\mathrm{IC}$ & Leadership \\
\cline { 2 - 7 } & Affinitive Climate & $.420^{* *}$ & $.526^{* *}$ & $.484^{* *}$ & $.665^{* *}$ & $.669^{* *}$ \\
\hline Authoritarian Climate & $.432^{* *}$ & $.503^{* *}$ & $.366^{* *}$ & $.301^{* *}$ & $.508^{* *}$ \\
\hline Achievement Climate & $.350^{* *}$ & $.363^{* *}$ & $.361^{* *}$ & $.306^{* *}$ & $.438^{* *}$ \\
\hline & Organizational Climate & $.477^{* *}$ & $.548^{* *}$ & $.483^{* *}$ & $.502^{* *}$ & $.639^{* *}$ \\
\hline \multirow{2}{*}{$p<.01$}
\end{tabular}

From Table 10, it is discovered that the overall relationship between Transformational Leadership and Organizational Climate of educational institutions along Thai-Cambodian borders is at high level with the correlation coefficient at .639. While considering for each dimension, it was found out that the Individualized Consideration (IC) is highly correlated with the Affinitive Climate with the correlation coefficient of .669. And affinitive climate and authoritarian climate is moderately correlated with inspirational motivation with the correlation coefficient at .526 \& .503 respectively. Further relationship between Idealized Consideration (IC) is least correlated with the Authoritarian Climate with the correlation coefficient of.301. Hence hypothesis is accepted

\section{Discussion}

Transformational Leadership of educational institutions or school administrators along the Thai - Cambodian borders is at high level. While considering each dimension, it was found out that the leadership is proved at the high level.

Organizational Climate of educational institutions along the Thai-Cambodian borders have good organizational climate, which is at high level. While considering for each dimension, it was found that all aspects scores high, which indicates a good sign of organizational climate.

Transformational Leadership of educational institutions or school administrators based on basic profile of the 
respondents revealed that female respondents agreed the existence of Transformational Leadership, which is higher than the male respondents. The medium sized schools agreed that the existence of Transformational Leadership was at high level of small-sized schools, and also the administrators agreed the existence of transformational leadership at high level, when compared to teachers. Further it was found that significant difference exists among the respondents based on gender and size of schools towards transformational leadership, whereas significant difference doesn't exist for individual dimensions of transformational leadership based on working status.

Organizational Climate of educational institutions along the Thai-Cambodian borders, it was found that female respondents agreed that organizational climate prevailing at Educational institutions was high, when compared to male respondents. And the medium-sized schools also agreed that the educational institutions or schools have good Organizational Climate, which was higher than the level of small-sized schools. Further, when compared with working status of the respondents, administrators agreed the existence Organizational Climate, which was higher than the level of teachers. Further it was found that significant difference exists among the respondents based on gender, size of schools and working status towards organizational climate. The relationship between Transformational Leadership and Organizational Climate of educational institutions along the Thai-Cambodian borders was at high level with the correlation coefficient of .639. Whereas the individual dimensions of both organizational climate and transformational leadership are moderately/least correlated, except Individualized consideration with affinitive climate at .665 levels. Further there was a positive association between the dimensions, but strong association was not found.

\section{Conclusion}

From the study it can be concluded that the transformational leadership and organizational climate at educational institutions along Thai-Cambodian borders was prevailing at high level and showed positive result, because, the educational institutions in Thailand are preparing themselves to integrate into ASEAN economic community. The study found that gender, size of school and working status of respondents have affected the level of Transformational Leadership and Organizational Climate of educational institutions. Moreover, it was also found out that female respondents, medium-sized schools and administrators have greater influence on transformational leadership and organizational climate. The point to ponder out here is small-sized schools could be supported to accelerate the growth to integrate into the ASEAN economic community. There was also a positive association between transformational leadership and organizational climate, but strong association was not found. Thus, the schools need to strengthen the relationship to compete into the ASEAN economic community.

\section{Suggestion}

The educational institutions should develop Transformational Leadership to create the good Organizational Climate in schools, which is essential to prepare them to compete/integrate into the ASEAN community. Small-sized schools could be given more importance to develop them in various aspects of transformational leadership and organizational climate. The government can take measures to encourage the educational institutions to prepare them for entering into ASEAN economic community. More studies can be conducted, by considering various factors that affect the readiness of educational management to integrate into the ASEAN Economic Community, along the Thai-Cambodian borders and also along other border areas.

\section{References}

ASEAN Department. (2009). Introduction to ASEAN. Bangkok: Department of ASEAN.

Bass. (1985). Leadership and Performance Beyond Expectations. New York: Free Press.

Gregopoulos, B., 1965. Normative structure variables and organizational behavior. Human. Relations., 18: 115-170

Litwin, G. H., \& Stringer, R. A. (1968). Motivation and organizational climate. Boston: Division of Research, Harvard Business School.

Moolenaar, N. M., Daly, A. J. \& Sleegers, P. J. C. (2010). Occupying the principal position: examining relationships between transformational leadership, social network position, and schools' innovative climate. Educational Administration Quarterly, 46(5), 623- 670 .

Nakrob Rawangkarn and Naruenant Suriyamanee. (2012). The role of educational institution administrators and capacity development in preparations for stepping into ASEAN Economic Community. Study Book Material. Bangkok: Faculty of Social Science and Humanities, Mahidol University.

Office of the Basic Education Commission. (2011). The Development of Standards and Strategies for School Improvement to Enter the ASEAN Economic Community, under the Office of Basic Education Commission. Bangkok: Office of the Basic Education. 
Ministry of Education.

Phothong, R. (2016), A study of personal characteristic, leadership and work climate affecting the operating employees engagement in the organization in Samut Prakan Area. MBA thesis., Graduate School, Bangkok University, Thailand. http://dspace.bu.ac.th/ jspui/handle/123456789/1852

Praepat Yodkaew. (2012). ASEAN Studies. Study Book Material. Nakhon Pathom: Faculty of Humanities and Social Sciences, Nakhon Pathom Rajabhat University.

Robbins. (1990). Organization Climate: A Review of theory and research. Psychological Bulletin.

Secretariat Office of the Education Council. (2006). The Comparative Research on Educational Reform of the countries in ASEAN Group. Bangkok: Parbpim Printing

Secretariat Office of the Education Council. (2009). The Proposal on Educational Reform in the Second Decade (BE 2552-2556). Bangkok: Secretariat Office of the Education Council, Ministry of Education.

Thani Sukasem. (2012). ASEAN: Past, present and future to ASEAN Economic Community 2015. Graduate Studies Network Academic Journal, 2 (2): 1-18.

Thira Rooncharoen. (2007). As a Professional in the Educational Management in the Age of of Educational Reform. Bangkok: Kaofang.

Troy A McCarley, Michelle L Peters and John M Decman. (2014). Transformational leadership related to school climate-A multi-level analysis. Educational Management Administration Leadership, doi: 10.1177/1741143214549966 